\title{
Flow Coefficient Analysis for a Globe Valve by using CFD
}

\author{
JVS Praveen ${ }^{1}$, Mehboob Pathan ${ }^{2}$ \\ ${ }^{1}$ Jr. Engineer, R\&D Department, Hawa Valves India Pvt. Ltd., Navi Mumbai. Maharashtra \\ ${ }^{2}$ R\&D Department Head \& Chief Technical Officer (CTO), Hawa Valves India Pvt. Ltd., Navi Mumbai, Maharashtra
}

\begin{abstract}
The valve selections criteria involves determination of valve coefficient, flow characteristics, shutoff requirements, body end connections, pressure classes, face to face dimensions, body and trim material selections, gasket and packing selection and process flow parameters. The measurement commonly applied to the valves is the valve coefficient (Cv) which is also known as flow coefficient. When selecting a valve for a particular application, the $C v$ is used to determine the valve size that will best allow the valve to pass the required flow rate, while providing stable control of the process fluid. This paper presents the research of Flow Coefficient analysis for a Globe Valve by using Computational Fluid Dynamics (CFD).The globe valve is the most commonly found control valve in the process industry due to its simple design, versatility of application, ease of maintenance and ability to handle a wide range of pressures and temperatures. Globe valves are used in both gas and liquid services. The flow system with Globe valve is complex structure and has nonlinear characteristics. In this paper, three-dimensional numerical simulations and experiment were conducted to observe the flow pattern and to measure valve flow coefficient and flow fluctuations when globe valve with different flow rate and uniform incoming velocities were used in a pipeline system. These results not only provide user with the access of understanding the flow pattern of the Globe valve with different flow rate and velocities, but also were made to determine the methods which could be adopted to improve the performance of the valve.
\end{abstract}

Keywords: CFD, Globe Valve, Flow Coefficient, Numerical Equations

\section{Introduction}

The Control Valve plays a very important part in the automatic control of modern plants, which depend on the correct distribution and control of flowing liquids or gases. Such control, weather for the exchange of energy, reduction of pressure, or simple to fill a tank, depends on some form of Final control element to do the job.

A control valve functions as a variable resistance in a pipeline. It provides a pressure drop by changing the turbulence in the process fluid or, in the case of laminar flow, the pressure drop is caused by the changed valve resistance or drag. This pressure drop process is often called throttling. A control valve is the most important single element in any fluid handling systems, because it regulates the flow of fluid to the process.

By definition, a globe valve is a linear-motion valve characterized by a globe style body with a long face to face dimension that accommodates smooth, rounded flow passages[4]. The advantages of globe valves are many hence their overall popularity. Generally, globe valve are quite versatile and can be used in a wide variety of services. The same valve can be used in dozens of different applications as long as the pressure and temperature limits are not exceeded. This versatility allows for reduction in spare parts inventory and maintenance training. Their simple linear motion design permits a wider range of modifications than other valve styles [1].

Because of the linear motion, the force generated by the actuator or actuation system is transferred directly to the regulating element; therefore, a minimal amount of the energy to the regulating element is lost. On the other hand, rotary valves lose some transfer energy and accuracy because of the dead band associated with linear- to rotary - motion linkage. For this reason, globe valves are capable of high performance and are used in applications were such performance is mandatory.

A major advantage to using globe control valves is their ability to withstand process extremes. They are designed to work in extremely high pressure drops, handling pressure differentials of thousands of pounds of pressure.

Steady flow of a Newtonian, incompressible fluid was assumed. The governing equations were solved using the SIMPLE algorithm [1].

Parts of Typical Globe Valve are:

1) Body is main pressure containing structure and it contains of all of the valves' internal parts.

2) Bonnet provides leak-proof closure for valve body.

3) Disc is closure member of the valve.

4) Stem servers as a connector from the actuator.

\subsection{Incompressible Flow}

When the fluid density does not change with changes in pressure, the fluid is incompressible. Water density changes very little with changes in pressure and is generally treated as an incompressible fluid.

Air is compressible, but if pressure changes are small in comparison with some nominal value, the corresponding changes in density are small also and incompressible quations work quite well in describing the flow. The degree to which the fluid density changes with pressure is related to the speed of sound in the fluid. Thus, assuming that the flow

Volume 6 Issue 12, December 2017 


\section{International Journal of Science and Research (IJSR) \\ ISSN (Online): 2319-7064}

Index Copernicus Value (2015): 78.96 | Impact Factor (2015): 6.391

is incompressible is equivalent to assuming that the speed of sound is infinite. When the local Mach number is less than 0.2 to 0.5 compressibility effects can often be ignored.

\subsection{Flow Coefficient.}

The valve flow coefficient is an inherent parameter which measures the valve capacity. It depends on valve type, diameter of valve, opening rate of valve and operating fluids. $\mathrm{Cv}$ is defined as the floe in cubic meter per hour of water at a temperature $5-40^{\circ} \mathrm{C}$ with a pressure drop across the valve of 1 bar.

$$
\mathrm{Cv}=\frac{q}{N 1 * F p * \sqrt{\frac{P 1-P 2}{G f}}}
$$

Where

$\mathbf{q}$ is the volume flow rate in $\mathrm{m} 3 / \mathrm{hr}$

$\mathbf{P 1}$ and $\mathbf{P 2}$ are inlet and outlet pressures

Gf is the specific gravity

Correction Factor, $\mathbf{F p}=1$

Numerical Constant, $\mathbf{N 1}=0.862$

The valve characteristic is a plot of the $\mathrm{Cv}$ versus percentage opening of the valve. The plot is indicative of how the flow rate will change with a change in percentage opening of the valve.

\subsection{CFD}

Computational fluid dynamics (CFD) is the science of predicting fluid flow, heat and mass transfer, chemical reactions, and related phenomena by solving numerically the set of governing mathematical equations.

\section{Literature survey}

[1] Philip L.Skousen, Revised to include details on the latest technologies, Valve Handbook, Third Edition, discusses design, performance, selection, operation, and application. This updated resource features a new chapter on the green technology currently employed by the valve industry, as well as an overview of the major environmental global standards that process plants are expected to meet. The book also contains new information on: valves used in the wastewater industry, applying emergency shutdown (ESO) valves.

[2] Qin Yang, Zhiguo Zhang, presents the researches of the authors in modeling and simulation of the stop valves. The flow system with stop valves is complex structure and has non-linear characteristics, because the construction and the hydraulic phenomena are associated of stop valves. In this paper, three dimensional numerical simulations were conducted to observe the flow patterns and to measure valve flow coefficient and flow fluctuations when stop valve with different flow rate and uniform incoming velocity were used in a valve system. The spectra characteristics of pressure fluctuation on the flow cross section were also presented here to investigate the wake induce of the valve part.

[3] Romil Khowal, presents an experimental method to calculate the flow coefficient value of the valve, but the setup

for the experimental validation is not readily available as these valves work at high pressure. This paper compares the flow coefficient value at different openings of the valve calculated by ANSYS Fluent 14.5 with the experimental values. The purpose of this paper is to define the boundary condition for the CFD analysis of the valve and to reduce the experimental validation for different sizes and openings and hence reducing the overall expense.

[4] Alexandre Joel Chorin, presents a finite difference method for solving the Navier-Stokes equations for an incompressible fluid has been developed. This method uses the primitive variables, i.e. the velocities and the pressure, and is equally applicable to problems in two and three space dimensions.

[5] Martin Burg, lecture is to give an overview on modern numerical methods for the computation of incompressible flows. They start with a short introduction to fluid mechanics, including the derivation and discussion of the most important models and equations. The numerical methods discussed in the subsequent part are ordered due to the model they solve, i.e., we start with the stationary Stokes problem, a linear saddle- point problem, then proceed to stationary Navier Stokes, which adds the complication of a nonlinear equation, and finally discuss the in stationary Navier-Stokes equations, which adds time discretization. In all cases, we shall discuss modern discretization strategies, their major properties, and the solution of the discretized equations.

[6] Benjamin Seibold, presented a simple numerical method for solving the Navier-Stokes equations. It contains fundamental components, such as discretization on a staggered grid, an implicit viscosity step, a projection step, as well as the visualization of the solution over time.

[7] P Howard, provided Partial Differential Equations in Mat Lab.

[8] J.W. Hutchison, This publication was prepared under the direction of the final control elements committee of ISA's Process Measurement and Control Division.

This hand book is intended to acquaint engineers with the factor of control valve design and application and to assist instrument engineers in the selection of the best valve body, actuator and accessories of application.

[9] Howard C. Elman, IFISS is a graphical Matlab package for the interactive numerical study of incompressible flow problems. It includes algorithms for discretization by mixed finite element methods and a posteriori error estimation of the computed solutions. The package can also be used as a computational laboratory for experimenting with state-of-the art preconditioned iterative solvers for the discrete linear equation systems that arise in incompressible flow modeling. A unique feature of the package is its comprehensive nature; for each problem addressed, it enables the study of discretization and iterative solution algorithms as well as the interaction between the two and the resulting effect on overall efficiency.

\section{Volume 6 Issue 12, December 2017}




\section{International Journal of Science and Research (IJSR) \\ ISSN (Online): 2319-7064 \\ Index Copernicus Value (2015): 78.96 | Impact Factor (2015): 6.391}

[10] Arkelyan Erik, In the following paper they consider Navier-Stokes problem and it's interpretation by hyperbolic waves, focusing on wave propagation. We will begin with solution for linear waves, then present problem for non-linear waves. Later we will derive for numerical solution using PDE's. Also we will design a Matlab program to solve and simulate wave propagation.

\section{Problem Definition}

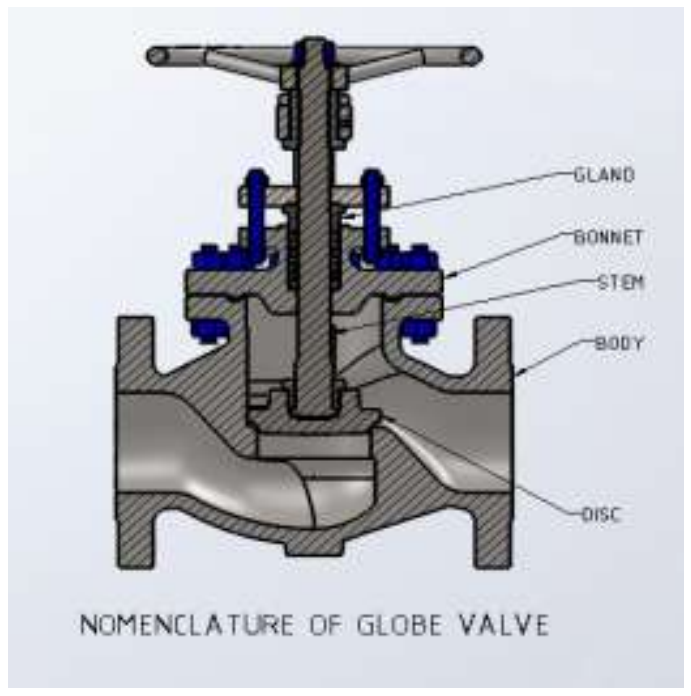

Figure 1: Nomenclature of Globe valve

Figure 1 shows the sketch and nomenclature of a globe valve (4IN300CL Model) investigated in this study.

- Ten cases are modeled \& analyzed in this paper by using ANSY CFD.

- Experimental setup is installed for verification of obtained values.

Finally we compare all the results.

\section{Governing Equations}

The actual pressure drop $\Delta \mathrm{P}$ is calculated using the $\mathrm{Cv}$ equation for liquid[11].

Chocked flow can be checked by finding the liquid pressure - recovery factor $F_{L}$ which is 0.90 . Then the liquid critical pressure ration factor $\left(\mathrm{F}_{\mathrm{F}}\right)$ is calculated by using the equation.

$\mathrm{F}_{\mathrm{F}}=0.96-0.28 \sqrt{\frac{P_{V}}{P_{C}}}$

Where

$\mathrm{P}_{\mathrm{V}}=$ Vapor pressure

$\mathrm{P}_{\mathrm{C}}=$ Critical pressure

After determining $F_{L}$ and $F_{F}$ these numbers are used in the chocked pressure drop.

A comparison should be made between the actual pressure drop and chocked pressure drop.

$\Delta \mathrm{P}_{\text {cavitation }}=\mathrm{F}_{\mathrm{L}}^{2}\left(\mathrm{P}_{1}-\mathrm{P}_{\mathrm{V}}\right)$
In this case actual pressure drop is greater than the pressure drop associated with incipient cavitation. This can be interpreted to mean that, although cavitation is occurring in the service, the cavitation is not causing the flow to chock.

\subsection{Equations of Fluid Flow}

The conservation laws of energy can be used in the analysis of flowing fluids.

The Bernoulli's equation can be considered to be a statement of the conservation of energy principal appropriate for flowing fluids. It is one of the most important equations in fluid mechanics. It outs into a relation pressure and velocity in an inviscid incompressible flow[6].

The general energy equation is simplified to:

$$
p_{1}+\frac{1}{2} \rho v_{1}^{2}+\rho g h_{1}=p_{2}+\frac{1}{2} \rho v_{2}^{2}+\rho g h_{2}
$$

Where

$\mathrm{h}=$ height above reference level $(\mathrm{m})$

$\mathrm{v}=$ average velocity of fluid $(\mathrm{m} / \mathrm{s})$

$\mathrm{p}=$ pressure of fluid $(\mathrm{Pa})$

$\mathrm{g}=$ acceleration due to gravity $(\mathrm{m} / \mathrm{s} 2)$

\subsection{Navier-Stokes equation}

A finite difference method for solving the Navier-Stokes equations for an incompressible fluid has been developed. This method uses the primitive variables, i.e. the velocities and the pressure, and is equally applicable to problems in two and three space dimensions. Essentially it constitutes an extension to time dependent problems of the artificial compressibility method introduced in for steady flow problems [8].

The equations to be solved can be written in the dimensionless form [8]

$$
\begin{aligned}
\partial_{i} u_{i}+R u_{j} \partial_{j} u_{i} & =-\partial_{i} p+\Delta u_{i}+E_{i}, \quad \Delta \equiv \sum \partial_{j}^{2}, \\
\partial_{j} u_{j} & =0
\end{aligned}
$$

Where $u_{i}$ are the velocity components, $E_{i}$ the external forces, $p$ is the pressure, and $R$ the Reynolds number, $\delta_{i}$ denotes differentiation with respect to the space variable $\mathrm{x}_{\mathrm{i}}$, and $d_{i}$ differentiation with respect to the time.

Problem where the velocities or their derivatives are prescribed at the boundary or where some boundary conditions are replaced by periodicity conditions have been investigated. For simplicity, we shall describe the case where the velocities are given at the boundary and shall assume that a Cartesian coordinate system is used. An important feature of the method is the use of equation (2) rather than a derived equation for determining the pressure. This makes it possible to satisfy the equation of continuity at the boundary and determine the pressure in a natural way. 


\section{International Journal of Science and Research (IJSR)}

ISSN (Online): 2319-7064

Index Copernicus Value (2015): 78.96 | Impact Factor (2015): 6.391

The following service conditions are given in imperial units:

Liquid $=$ water

Critical Temperature $\left(\mathrm{P}_{\mathrm{c}}\right)=230 \mathrm{bar}$

Temperature $=150^{\circ} \mathrm{C}$

Flow rate $\mathrm{Q}=1000 \mathrm{gal} / \mathrm{min}$

Flow characteristic $=$ Equal Percentage.

Nominal Speed $=10 \mathrm{~m} / \mathrm{s}-20 \mathrm{~m} / \mathrm{s}$

\section{Results \& Discussions}

The Analysis is run for ten opening conditions. The results of the same is listed in the below table.

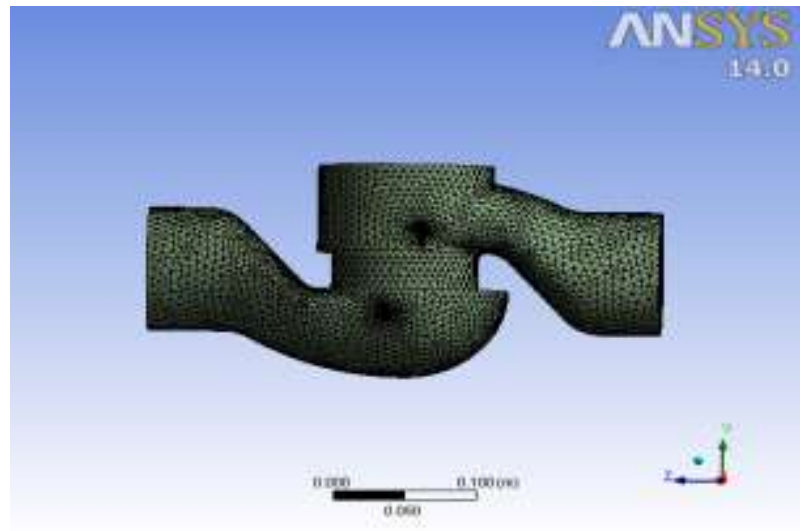

Figure 2: Meshing of Flow path

The purpose of meshing is to decompose the solution domain into an appropriate number of locations for accurate results.

\subsection{Velocity contour}

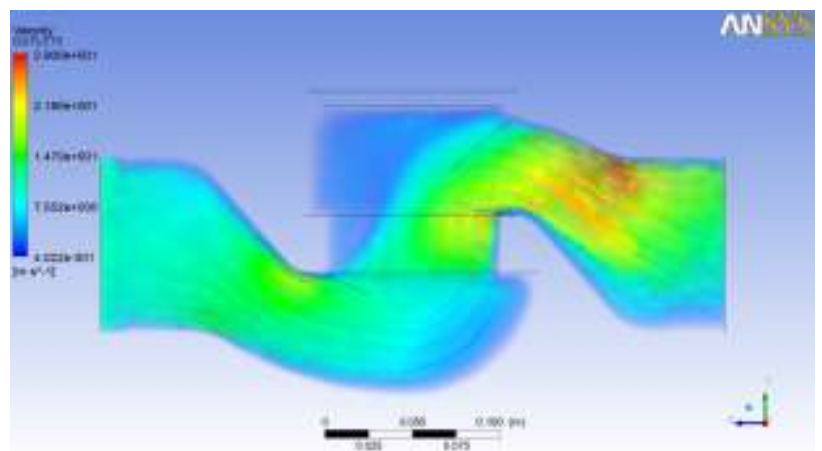

Figure 3: 100\% Flow Open

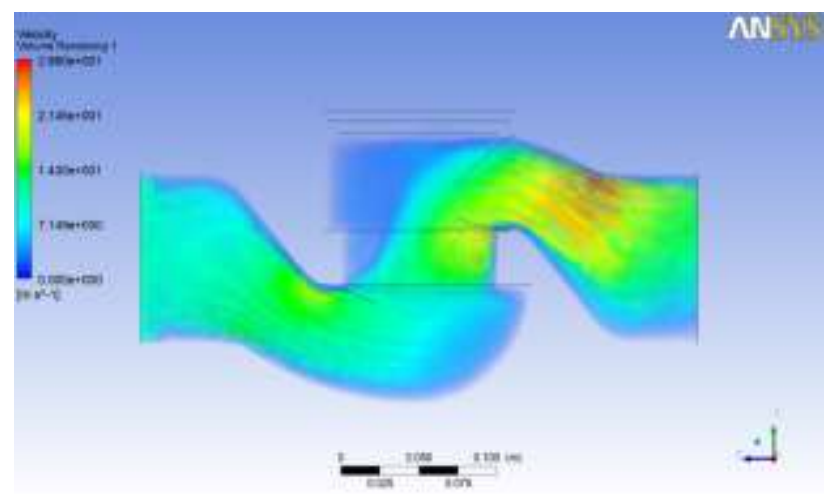

Figure 4: 90\% Flow Open

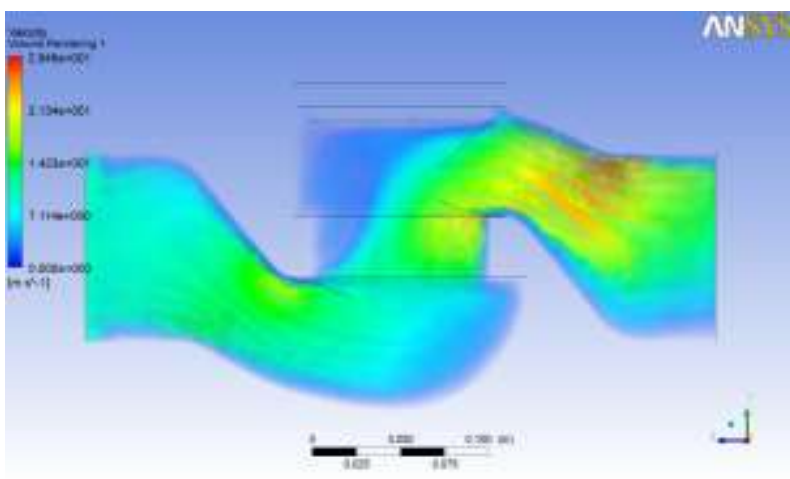

Figure 5: $80 \%$ Flow Open

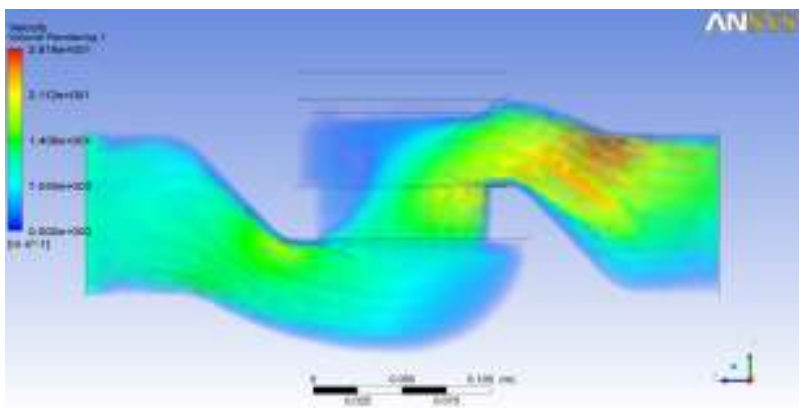

Figure 6: 70\% Flow Open

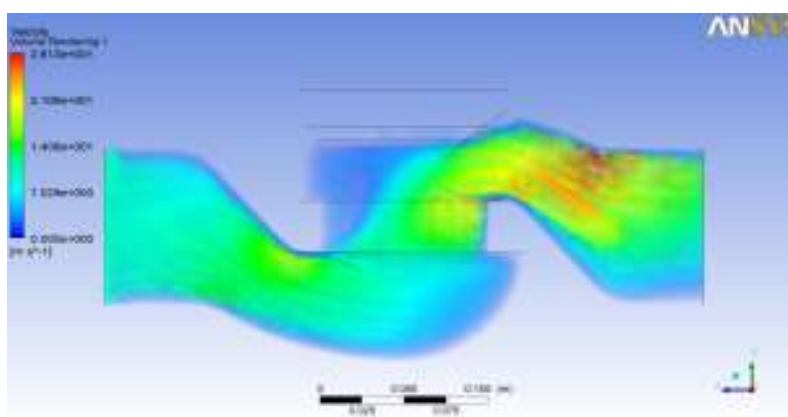

Figure 7: 60\% Flow Open

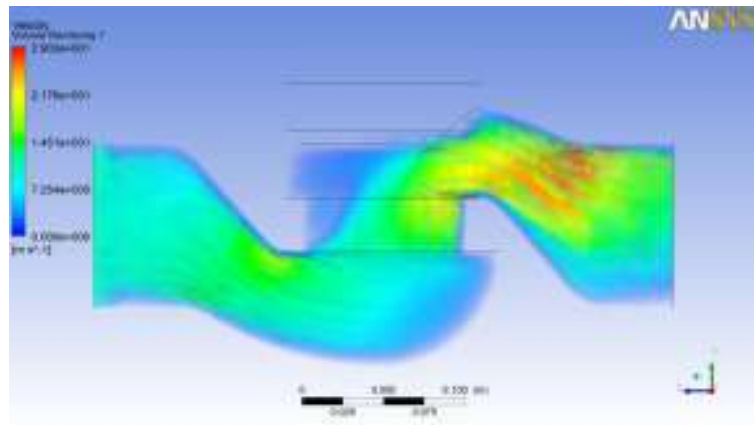

Figure 8: 50\% Flow Open

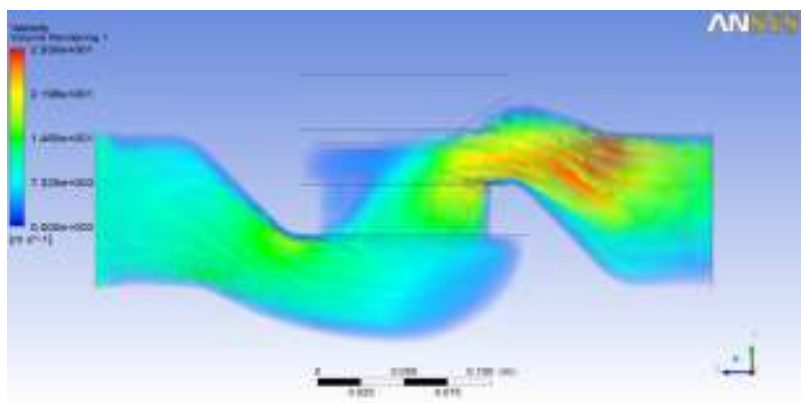

Figure 9: 40\% Flow Open

Volume 6 Issue 12, December 2017

www.ijsr.net

Licensed Under Creative Commons Attribution CC BY 


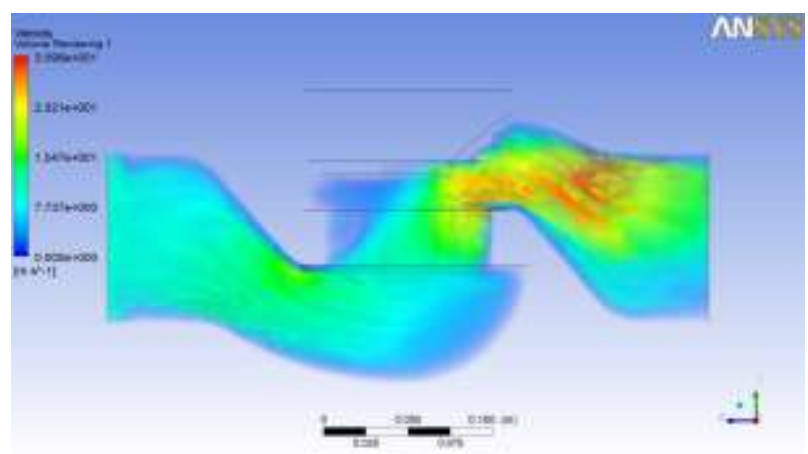

Figure 10: 30\% Flow Open

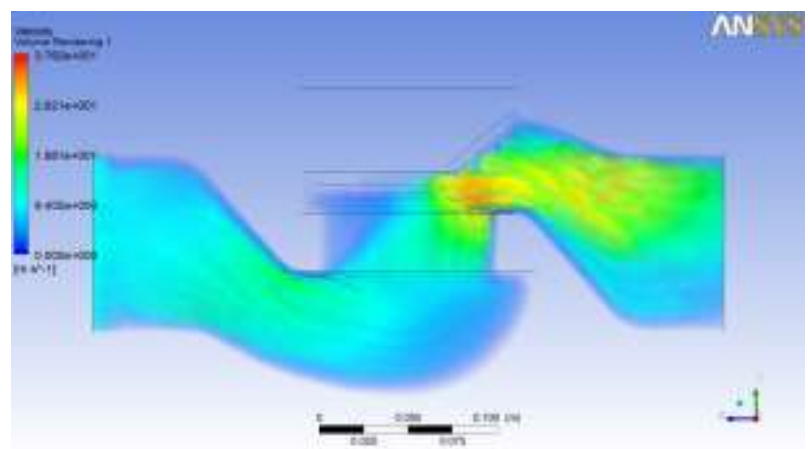

Figure 11: 20\% Flow Open

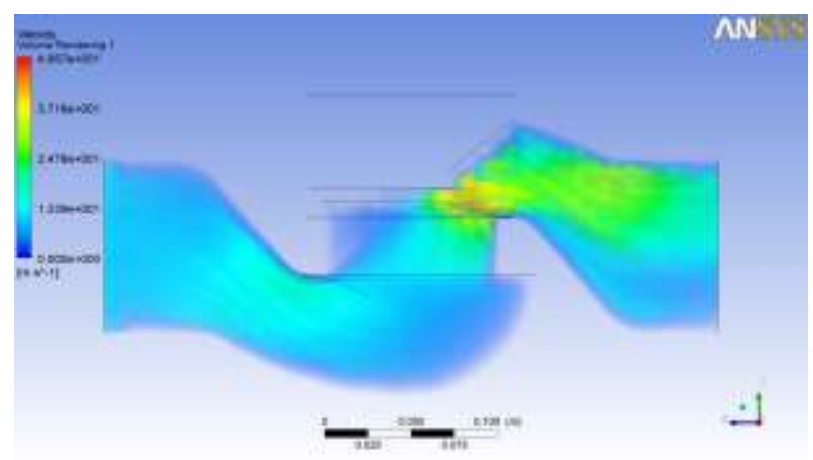

Figure 12: 10\% Flow Open

\subsection{Pressure contour}

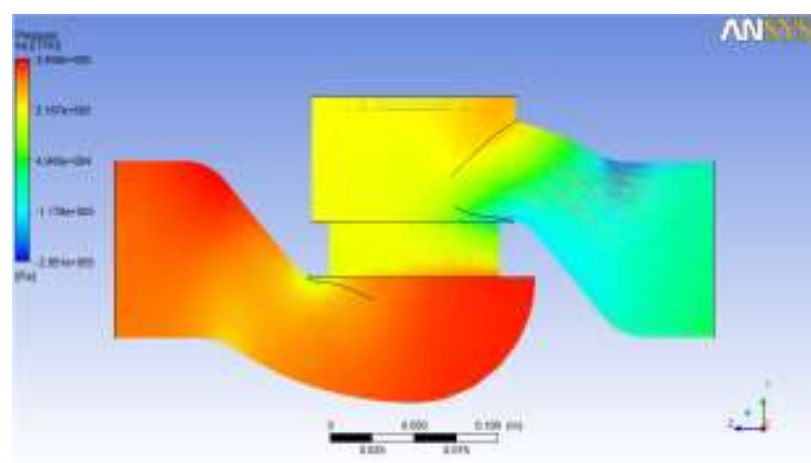

Figure 13: 100\% Flow Open

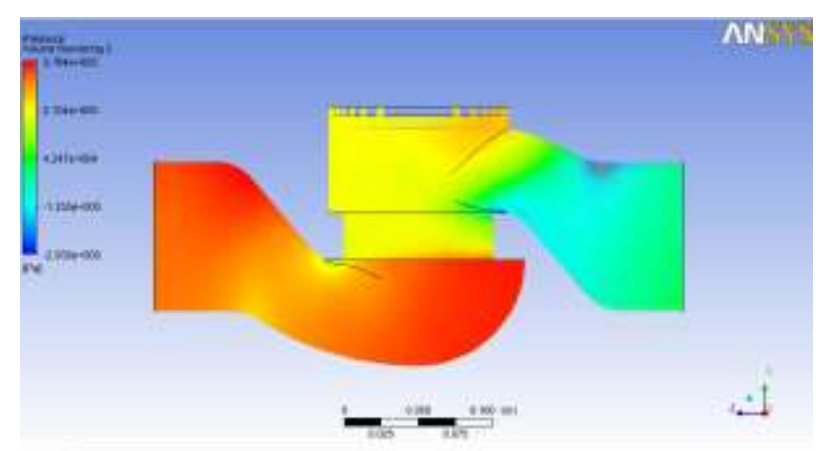

Figure 14: 90\% Flow Open

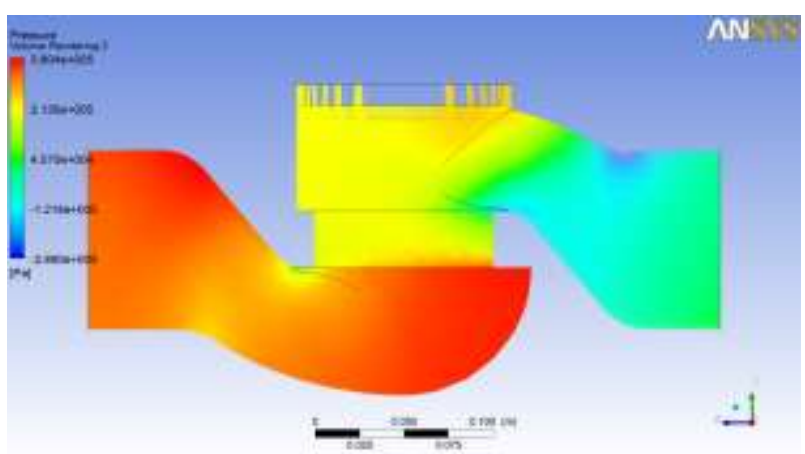

Figure 15: 80\% Flow Open

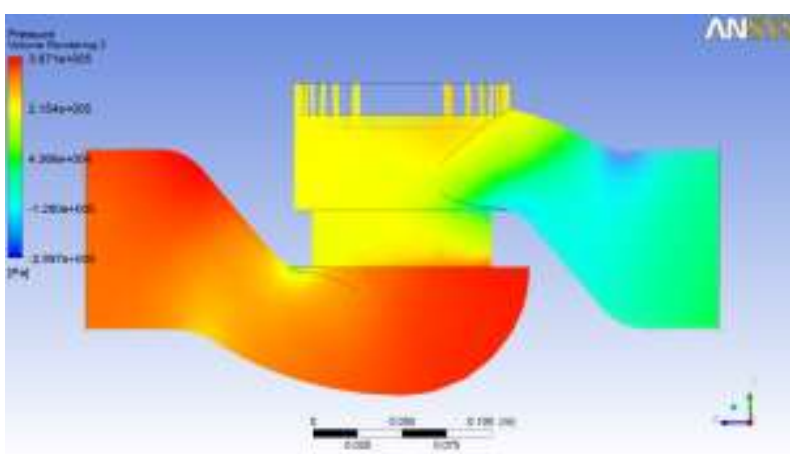

Figure 16: 70\% Flow Open

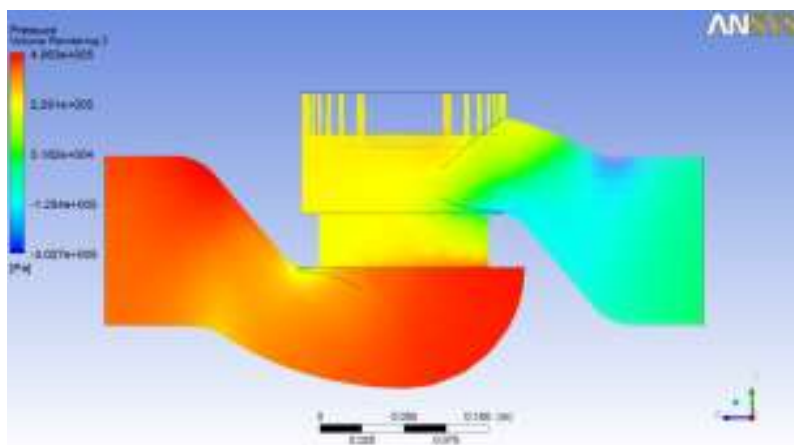

Figure 17: 60\% Flow Open

Volume 6 Issue 12, December 2017

www.ijsr.net

Licensed Under Creative Commons Attribution CC BY 


\section{International Journal of Science and Research (IJSR)}

ISSN (Online): 2319-7064

Index Copernicus Value (2015): 78.96 | Impact Factor (2015): 6.391

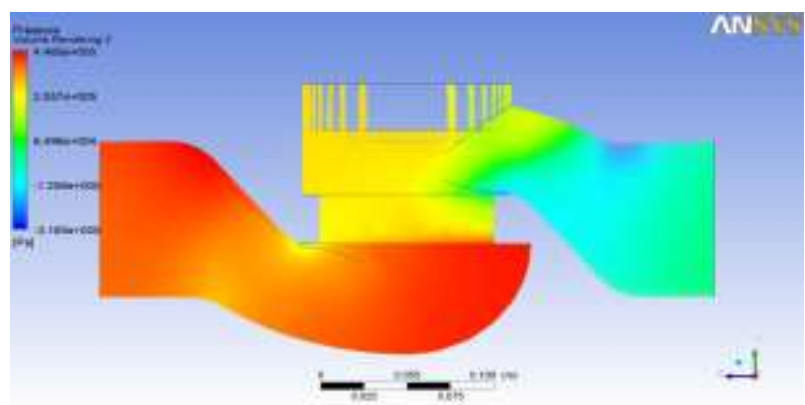

Figure 18: 50\% Flow Open

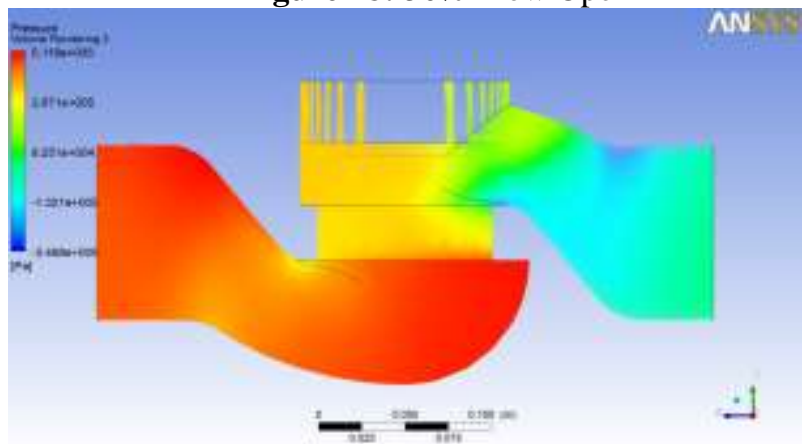

Figure 19: 40\% Flow Open

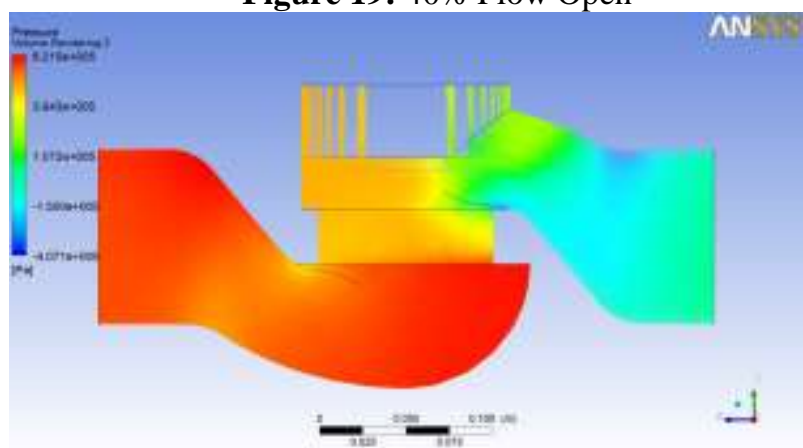

Figure 20: $30 \%$ Flow Open

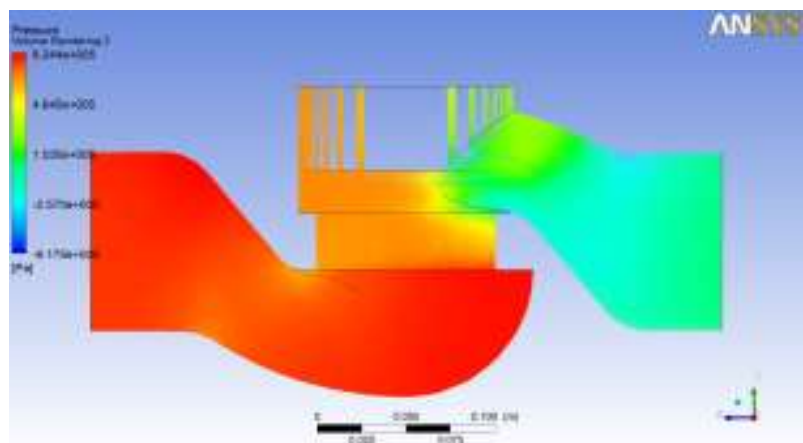

Figure 21: 20\% Flow Open

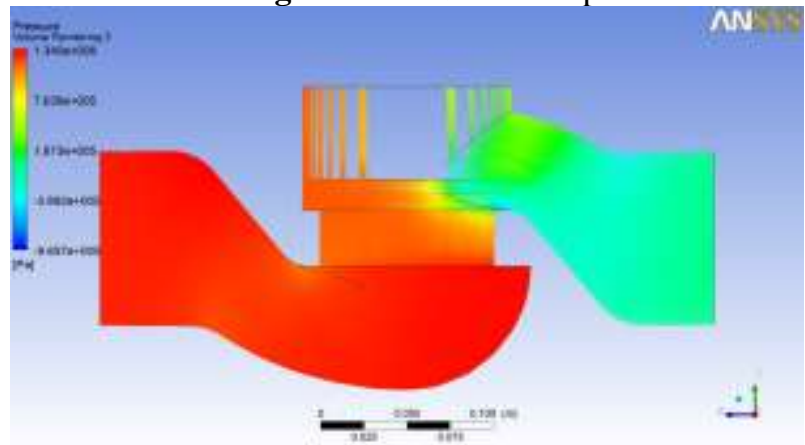

Figure 22: 10\% Flow Open
Table 1: Parameters at different openings

\begin{tabular}{|c|c|c|c|}
\hline $\begin{array}{l}\text { Sr. } \\
\text { No. }\end{array}$ & $\begin{array}{l}\text { Percentage } \\
\text { of Opening }\end{array}$ & $\begin{array}{l}\text { Outlet } \\
\text { Velocity (m/s) }\end{array}$ & $\begin{array}{l}\text { Pressure } \\
\text { Drop (psia) }\end{array}$ \\
\hline 1 & 100 & 29.00 & 48.58764 \\
\hline 2 & 90 & 28.60 & 48.73268 \\
\hline 3 & 80 & 28.460 & 48.54413 \\
\hline 4 & 70 & 28.160 & 49.80596 \\
\hline 5 & 60 & 28.120 & 51.41588 \\
\hline 6 & 50 & 29.020 & 55.33190 \\
\hline 7 & 40 & 29.300 & 62.26470 \\
\hline 8 & 30 & 30.950 & 74.59290 \\
\hline 9 & 20 & 37.620 & 104.55770 \\
\hline 10 & 10 & 49.270 & 167.18500 \\
\hline
\end{tabular}

Case 9 and Case 10 does not follow the pattern of the valves. The reason of the same is the opening of the valve, in both cases disc supports the fluid flow hence result in increase in outlet velocity.

Likewise Pressure drop also not follow the pattern of the valves. The reason is same of opening of the valve.

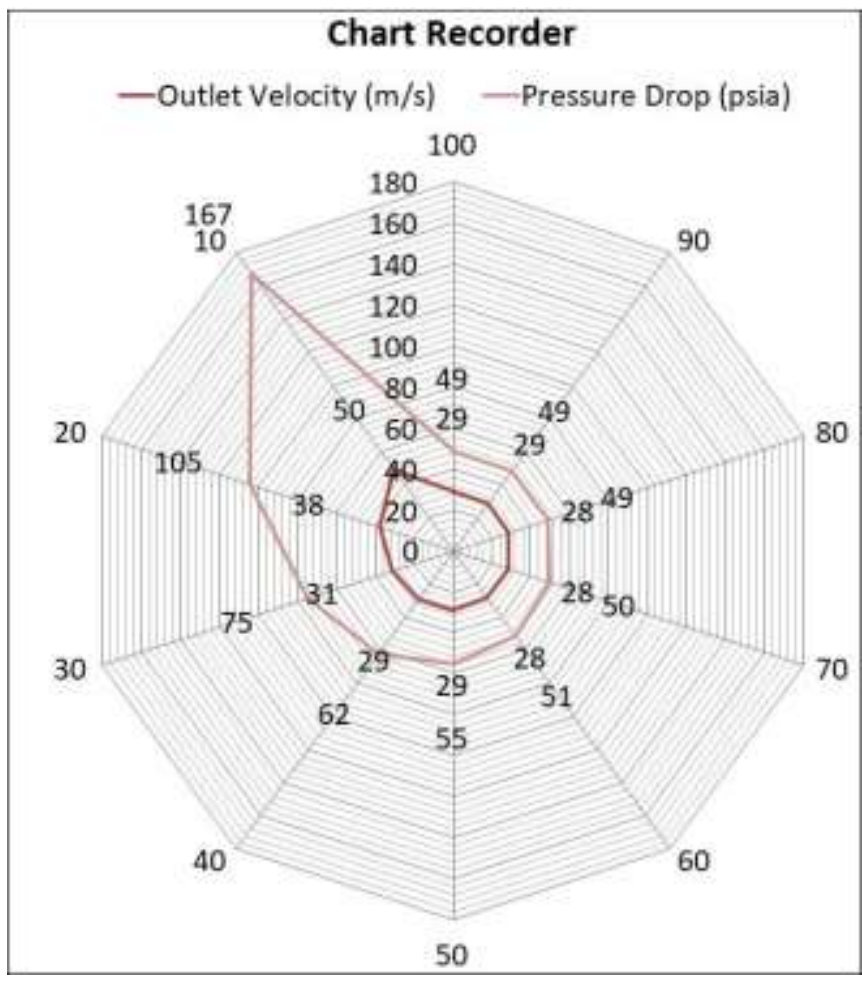

Figure 23: Pressure drop and Outlet Velocity Chart Recorder

Volume 6 Issue 12, December 2017

www.ijsr.net

Licensed Under Creative Commons Attribution CC BY 


\section{International Journal of Science and Research (IJSR) \\ ISSN (Online): 2319-7064}

Index Copernicus Value (2015): 78.96 | Impact Factor (2015): 6.391

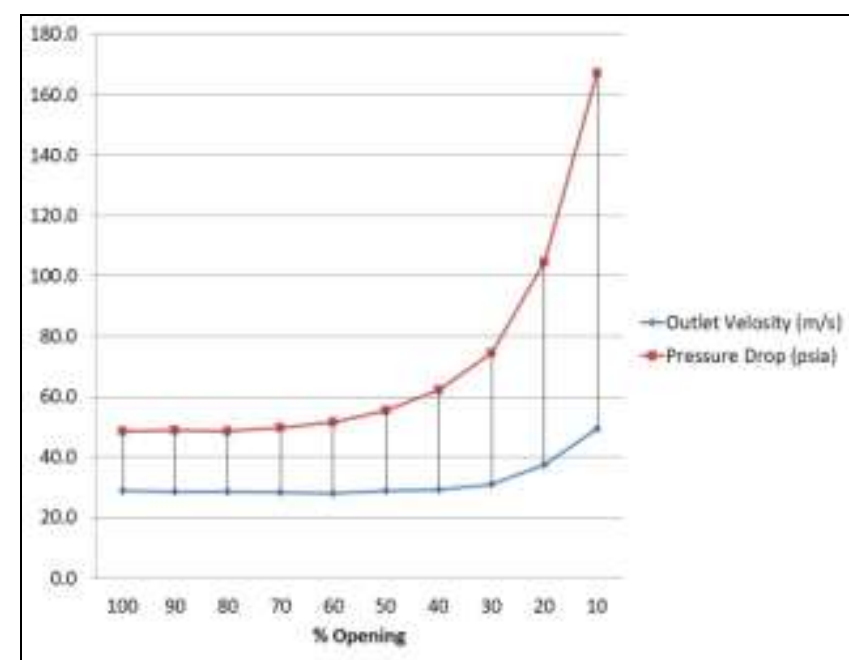

Figure 24: Pressure drop and Outlet Velocity Curve.

Table 2: Parameters at different openings

\begin{tabular}{|c|c|c|c|}
\hline Sr. No. & Percentage of Opening & $\mathrm{Cv}$ & $\mathrm{Kv}$ \\
\hline 1 & 100 & 139.090 & 119.905172 \\
\hline 2 & 90 & 138.880 & 119.724138 \\
\hline 3 & 80 & 139.150 & 119.956897 \\
\hline 4 & 70 & 137.370 & 118.422414 \\
\hline 5 & 60 & 135.21 & 116.560345 \\
\hline 6 & 50 & 130.330 & 112.353448 \\
\hline 7 & 40 & 122.860 & 105.913793 \\
\hline 8 & 30 & 112.250 & 96.7672414 \\
\hline 9 & 20 & 94.816 & 81.737931 \\
\hline 10 & 10 & 74.983 & 64.6408621 \\
\hline
\end{tabular}

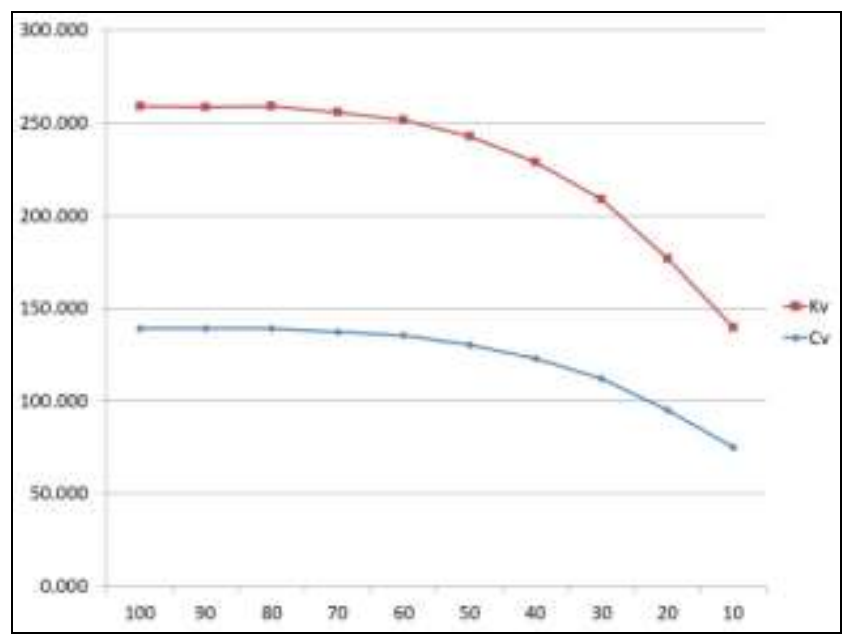

Figure 25: $\mathrm{Cv}$ and $\mathrm{Kv}$ Curve

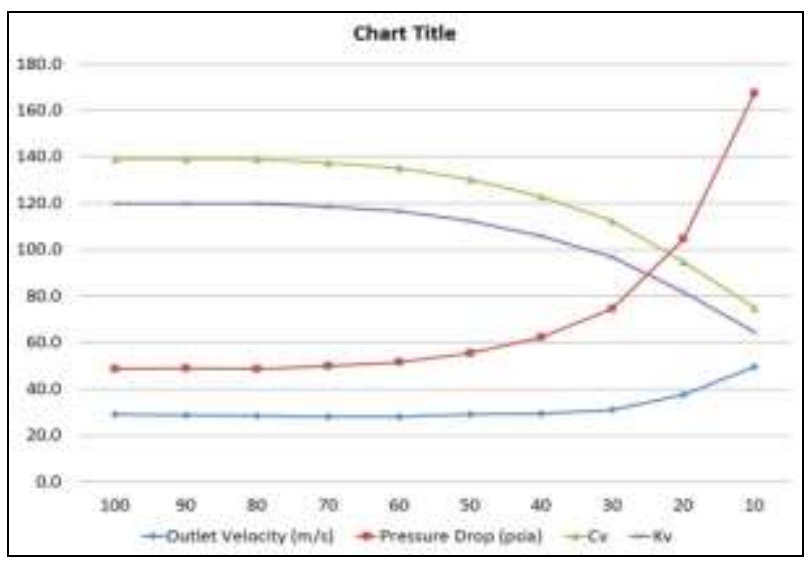

Figure 26: Parameters Vs \% Opening Curve

\section{Conclusion}

The modeling methodology for the Flow Coefficient estimation for a Globe valve has been systematically investigated by considering flow parameters. The conclusions are drawn as follows:

a) The variation in experimental value and the value from numerical method is about $14.51 \%$. In general practice up to $20 \%$ variation is considered.

b) The boundary conditions used in this paper are within permissible limits.

c) The numerical model values have a good agreement with those obtained by Experimental values, thereby supporting the validity of this approach.

\section{Future Scope}

The work covered in the thesis tries to solve Flow coefficient for a globe valve. Still there are some problems are left and are of interest were identified and are mentioned below:

Two problems with control valves are found at a high frequency in poorly performing control loops. These are:

- Dead band

- Stiction

\section{Deadband}

For a control valves, deadband refers to a range of controller signal that fails to trigger any activity of the valve. Deadband happens when the valve needs to change direction. To compensate for deadband, the controller must send additional output, which can cause the valve to overshoot its target position. This in turn causes the process to overshoot its set point.

There are several consequences of high deadband:

- Increased dead time

- More errors from load disturbances

- Higher possibility of rupturing pressure relief discs or vessels

- More oscillations in the control loop

- Increased control variance

\section{Stiction}

Another very common problem found in control loops is stiction. This is short for Static Friction, and means that the valve internals are sticky.

If a valve with stiction stops moving, it tends to stick in that position. Then additional force is required to overcome the stiction. The controller continues to change its output while the valve continues to stick in position. Additional pressure mounts in the actuator. If enough pressure builds up to overcome the static friction, the valve breaks free. The valve movement quickly absorbs the excess in pressure, and often the valve overshoots its target position. After this, the valve movement stops and the valve sticks in the new position.

Our Research is going now.

\section{Volume 6 Issue 12, December 2017




\section{International Journal of Science and Research (IJSR) \\ ISSN (Online): 2319-7064}

Index Copernicus Value (2015): 78.96 | Impact Factor (2015): 6.391

\section{About Company}

Hawa Valves are manufacturers and exporters of valves for application in critical hydrocarbon/oil and gas upstream, midstream, downstream, chemical, power, marine, mining and general industry. Hawa Valves have ISO 9001. ISO 14000, OHSAS 18000, SIL 3, CE/PED, ATEX certified and have American Petroleum Institute monogram licenses of API 600, API 6A, API 6D, API 6DSS and API 609.

The dedicated in house $R \& D$ facility is recognized by Government of India, Ministry of Science and Technology, Department of scientific and Industrial Research.

Hawa Valves hold many international patents.

"Hawa Valves India Pvt. Ltd. As a company is ready to meet all control valves needs in any environment or filed"

Likewise through a whole array of accomplishment including our vision, enthusiasm, flexibility, innovation product development and use of technology diversity of exports, emphasis on quality and shrewd business acumen indeed seems assured of a very bright future.

For more details: http://www.hawavalves.com/

\section{Acknowledgement}

Our sincere thanks to Mr. Javed A. Hawa, Managing Director of Hawa Valves India Pvt. Ltd. who encouraged and allowed to present this paper.

We also thank Mr. Chitta Nageswara Rao, (M.Tech, and M.B.A) for motivating and providing guidance.

\section{References}

[1] "Valve Handbook", by Philip L.Skousen MacGraw-Hill Publications, Third Edition.

[2] Qin Yang, "Numerical Simulation of fluid flow inside the valve" in procedian engineering 23 (2011) 543-550, Elsevier

[3] H. S. Ramanath, C. K. Chua. "Application of rapid prototyping and computational fluid dynamics in the development of water flow regulating valves". International Journal of Advanced Manufacturing Technology; 2006, vol. 30(9-10): p. 828-835.

[4] "ISA hand book of control valves" by J.W. Hutchison second edition.

[5] Taewoo Kim, Sulmin Yang, Sangmo Kang. "Numerical study on the flow characteristics of a solenoid valve for industrial applications. Wseas Transactions on Fluid Mechanics"; July 2010, Issue 3, Volume 5; p. 155164.J.

[6] Xue guan Song, Young Chul Park. "Numerical analysis of butterfly valve-prediction of flow coefficient snd hydrodynamics torque coefficient. Proceedings of the world congress on Engineering and computer science"; USA: San Francisco; 2007.

[7] Benjamin Seibold, "A compact fast Matlab code solving the incompressible navier-Stokes equations on
Rectangular domains" Massachusetts institution of technology, March 31, 2008.

[8] Alexandre joel chorin " The numerical solution of the Navier-strokes equations for an incompressible fluid" Communicated by E. Isaacson June, 1967

[9] Howard C.Elman, "A matlab toolbox for modeling incompressible flow" university of Maryland.

[10] Arkelyan Erik, "The numerical Solution of Navier Hyperbolic equations: shock wavw propagation" Numerical Analysis project from American University of Armenia.

[11] Martin Burger, "Numerical Methods for incompressible Flow" based on lecture notes by Rene pinnau, TU Darmstadt.

[12] Fritz J, "Failure Analysis of a Globe Valve" Ohio University

[13] Hoffmann, K.A, Chaing, S.T., Computational Fluid Dynamics Vol.1, Engineering Education System, Wichita, Kansas, 1998, ISBN 0-9623731-1-1-7.

[14] Prof. Mrs. V.J. Sonawane, "performance Evaluation of Globe valve as control valve using CFD software" Pump valves and systems, volume 6, issue 6, Jul-Aug 2015.

[15] P Howard, "Partial Differential Equations in MATLAB 7.0” Spring 2010.

[16] Numerical Solution of navier-stokes equations using FEMLAB, Umea University.

[17] ANSYS, “ANSYS Work bench User Guide," User Manual 2017.

[18] International Society of Automation, "Flow Equations for Sizing Control Valves, "ISA, North Carolina Standards ISA-75.01.01-2007,

[19] Brian Nesbitt, Hand book of valves and actuators, Elsevier, 2007.

[20] Louise Thoren Anna Budziszewski, CFD Simulation of a safety relief valve for improvement of a onedimensional valve modal in RELAP5, 2012.

[21] "Knowing More about valves", Principals \& practice ISBN81-7992-036-4, First Jaico Edition 2003.

\section{Author Profile}

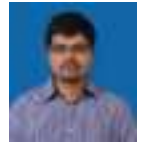

JVS Praveen, M.Tech in CAD/CAM and having 3.5 years' experience, currently a Jr. Engineer in R\&D Department of Hawa Valves India Pvt. Ltd.

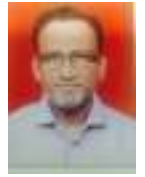

Mehboob Pathan, Currently R\&D Head and Chief Technical Officer of Hawa Valves, has over 28 years' experience in valve industry. Leading $\mathrm{R} \& \mathrm{D}$ and Technical departments, develop new product range, develop new equipment for various validation testing as per valve industry norms, upgrade existing equipment in line with latest industry updates, provide technical guidance, implement latest technologies in product developments, mentoring in skill development, participate in technical events worldwide, evaluate and resolve technical feasibility, visit end user sites such as offshore platforms, impart technical training to staff. Assist in developing new dies, fixtures, tooling and processes. Assist in developing latest machineries and equipment required for product development.

\section{Volume 6 Issue 12, December 2017}

